\title{
Simulation Study of Multi-Phase Multi-pole Induction Motor Drive for Electric Propulsion System \\ ${ }^{*} \mathrm{~S}$ V Umredkar, ${ }^{2} \mathrm{R}$ Keshri, ${ }^{3} \mathrm{M}$ M Renge, ${ }^{4} \mathrm{~V}$ B Borghate \\ ${ }^{1,3}$ Shri Ramdeobaba college of Engineering, Nagpur \\ ${ }^{2,4}$ Visvesvaraya National Institute of Technology, Nagpur \\ Email: umredkars@rknec.edu ; riteshkeshri@eee.vnit.ac.in; rengemm@rknec.edu; vbborghate@eee.vnit.ac.in
}

Received: 15th October 2019, Accepted: 31st January 2020, Published: 30th April 2020

\begin{abstract}
The induction motor has been proven to be one of the most suitable motors for the modern electric vehicle. Nevertheless, there is still an issue for its wider application to electric vehicle propulsion which is the difficulty in providing constant power operation for wide speed range of electric vehicle. Thus the inverter fed multi-phase multi-pole induction motor (MPMPIM) is becoming an attractive option for modern electric vehicle.

This paper presents a way to develop an inverter fed MPMPIM drive for electric propulsion which fulfils its crucial requirements like high starting torque, high power density, high reliability, high efficiency, etc. One of the important features of MPMPIM drive, due to higher number of phases and subsequent decrease in phase current, conduction losses are reduced considerably resulting in cost reduction and cooling with better mileage. With the use of MPMPIM drive technology fault tolerance capability of the electric propulsion system also improves.
\end{abstract}

Keywords

Multi-phase Multi-pole Induction Motor Drives, Torque-speed Characteristics, Finite Element Analysis

\section{Introduction}

The industrial revolution changed the way humans commuted from one place to the other. The animal driven carts were getting replaced with fuel driven automobiles. The discovery of crude oil as a viable source for such vehicles helped to setup assembly line and start mass production of such vehicles. The invention and commercialization of the IC engine based transportation system happens to be one of the most important discoveries. The transportation became fast and comfortable. The alarming rate of increase in the pollution levels of the human habitats and depleting non-renewable energy sources powering the industrial revolution has forced the science and engineering fraternity to look for viable alternate energy sources. [1] The vehicular traffic forms the major part of the pollution source especially in the cities. Electric vehicle technology has evolved significantly over last two decades making it one of the attractive and sustainable options for transportation. The electric vehicles have come up as the most viable alternative with clean power source and no pollution.

Basic requirement of electric propulsion system is to operate at constant power over a wide torque-speed range with good overload capacity and high efficiency. Brushed DC motor, synchronous brushed motor, Induction Motor (IM) and Permanent Magnet Synchronous Machines (PMSMs) [2] are some of the available drives for electric vehicles. Out of these, PMSMs is widely [3] used because of its high torque density capability. However, their cost and demagnetisation problem at high power rating [4] forces the researchers to look for other better options. IMs inherently have lower cost and are more robust than PMSMs.

Synchronous machines do not provide the flexibility to operate on wide speed range as the number of pole-pairs is defined from the rotor poles. However, in case of asynchronous machines it is possible to change the number of pole-pairs even during the operation [5] as the number of pole-pairs is defined from the stator side (winding MMF poles). This flexibility helps achieve better efficiency over a wide speed range in case of asynchronous machines. In Electric Propulsion system, IM is one of the better candidates due to its reliability, ruggedness, low maintenance and ability to operate in any environment. Traditionally available IM drives are not suitable for electric propulsion system [6][7]; hence MPMPIM drives offer better substitute to achieve electric propulsion requirements like high power density, high starting torque, etc. One of the important features of MPMPIM drive is it can operate above base speed at constant power with the help of flux weakening control.

\section{Methodology}

Multi-level inverter techniques upgrade the performance of MPMPIM drive. [14] MPMPIM drives have an inherent advantage of high phase number, reduced torque ripple and improved efficiency using two-level voltage excitation. But to achieve high starting torque which is required by electric propulsion system, number of poles has to be increased by reducing the number of phases in MPMPIM drives. Torque ripple increases as the number of phases decrease leading to inefficiency. Multi-level inverter topologies are best suited to reduce torque ripple and thereby improve efficiency of MPMPIM drives. But resulting increase in the device count of 
electric propulsion system along with control complexity limits the extension of conventional multi-level inverters for MPMPIMs. [9]

To improve the performance of MPMPIM drive by multi-level voltage generation, different pulse width modulation technologies can be used to control voltage source inverter(VSI) operation for example sinusoidal pulse width modulation (SPWM), space vector pulse width modulation (SVPWM) and carrier based pulse width modulation (CPWM). [8] The algebraic sum of voltages across the respective equal voltage pole coils (EVPCs) is the effective voltage across the phase of MPMPIM in case of high-pole operation. [11]

Fault tolerance capability, which is the ability of a drive to continue to operate even after being subjected to various types of fault, of MPMPIM drive increases due to high number of phases. [12] Multi-level inverter improves the reliability of the system due to its ability to sustain various faulty conditions. [13] Additionally, SVPWM can be used to improve dc-link utilization in low pole [8] mode and in high pole mode torque ripple is reduced by carrier-phase shift three phase SVPWM. To analyse the performance of MPMPIM drive, without hardware implementation, 2D Finite Element Analysis (FEA) is used. FEA simulates actual conditions of lamination geometries, core materials, and winding connections. [14]

\section{Pole-phase Modulation}

Manual configuration to achieve pole-phase modulation results in discontinuous torque and poor dynamic performance. In manual pole-phase modulation, it was required to de-energize the windings before changing the poles and the stator windings were then reconfigured using contactors which leads to discontinuous torque. With the advent of power electronic converters, the number of poles/phases can be changed seamlessly without any manual intervention. Primarily two techniques are applied to achieve this. Pole Amplitude Modulation (PAM) can help achieve variable speed only by changing poles while keeping the number of phases same. This technique provides only one degree of freedom with respect to change in pole-pairs. Pole-Phase Modulation (PPM) appears a better option as it helps alter both the numbers of phases and poles to achieve better control and freedom. [14][15]

The torque/power vs speed characteristics of an IM can be altered by manipulating the number of poles and phases. [10] These techniques provide additional degree of freedom, flexibility and reliability over traditional three-phase machines. It also improves the fault-tolerance by ensuring that the healthy phases keep working even in the event of a phase failure. The machine keeps running though at a lower efficiency.

MPMPIM come as a promising solution for electric propulsion requirements like high power density and high starting torque. [6] One of the important features of MPMPIM drive is that it can consistently operate above the base speed at constant power with the help of flux weakening control.

Multi-phase drives have many advantages over traditional three phase drives [7]:

- Torque ripple is reduced.

- Independent control of flux as well as torque.

- Reduction in the power rating requirement of deployed switches due to decrease in the DC link voltage of inverter.

- Increasing the number of poles reduces the current stress proportionally

- Better power handling capacity with reduced ratings of power electronic devices.

- More reliability at the system level, since a multi-phase drive can still be operated with an asymmetrical winding structure even when one or more inverter legs/machine phases are lost. The operation is maintained though at a reduced rating.

- $\quad$ Large number of phases provides much better fault tolerance.

For MPMPIM, the number of stator winding phases $(\mathrm{m})$ depends on the ratio of the number of slots (Q) and pole-pairs (p) as shown in equation (1), subject to the constraint that slots per pole per phase (q) must be same for all phase combinations.

$m=\frac{Q}{p}$

The coil pitch is same and constant for all coils and it cannot be changed during winding reconnection for pole changing. [15][17][18] Number of stator slots given in terms of pole pairs and the number of phases for a synchronous speed can be represented as shown in equation (2)

$Q=2 p_{1} * q_{1} * m_{1}=2 p_{2} * q_{2} * m_{2}$

\section{Torque-speed Operation}

The torque-speed characteristics of IC engine, EVs (ideal performance) and MPMPIM drive are as shown in the Fig. 1 [17]. Fig (1a) indicates the performance of the IC engine when coupled with a multi-gear system to achieve variable torque-speed characteristics. Fig 1(b) shows the ideal characteristics of a simple IM. Fig 1(c) shows the characteristics of MPMPIM which are very similar to the IC engine. [17] 


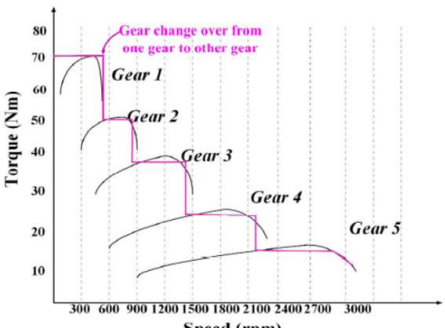

(a)

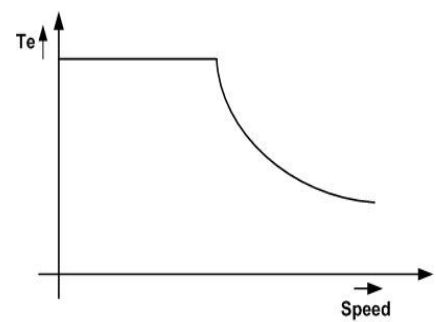

(b)

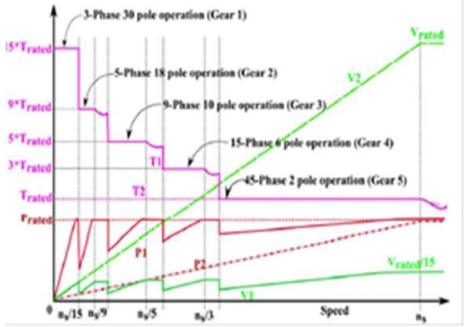

(c)

Fig. 1: Torque-speed Characteristics of (a) IC Engine (Umesh et al., 2017) (b) EV Ideal Performance Characteristics (Ehsani et al., 2007) (c) MPMPIM Drive (Umesh et al., 2017)

Simulation of MPMPIM for Proposed Drive with FEA Simulation

For this work a 48-pole IM drive is considered with 12 coils having 24 terminals. In order to achieve a geared performance without using mechanical gears the speed ratios of 1:1.25:2:4 are considered. The main dimensions of the IM are mentioned in Table 1 below. Out of the 24 terminals, 12 terminals on one side of each phase windings are shorted. This leaves 12 open terminals which can be fed by a 12-phase inverter. Four different pole-phase combinations were tried for this work. With the pole ratio $\mathrm{k}=2$ and $50 \mathrm{~Hz}$ supply frequency, when the IM was operated as 6-phase 4-pole machine, it resulted in synchronous speed of 1500 $\mathrm{rpm}$. The same IM with a pole ratio $\mathrm{k}=4$ and same supply frequency when operated as 3-phase 8-pole machine it gave a synchronous speed of $750 \mathrm{rpm}$. Thus wide range of speed control was obtained. The proposed drive offers high torque for hill climbing at high pole mode (3-phase 8-pole combination)and provides the high power for medium and high speed cruising at low pole mode (12-phase 2-pole combination)thereby improving the transient performance of the drive. Established constraint that the pole ratio must be a positive odd integer greater than one to bring more clarity in the generalization of PPM is invalidated by proposed system in this work. Pole ratios can even be positive even integer greater than one as derived in the following equation.

$$
q=\frac{48}{8 * 3}=\frac{48}{6 * 4}=\frac{48}{4 * 6}=\frac{48}{12 * 2}=2
$$

\begin{tabular}{|l|l|l|l|}
\hline General Data & Star connection; Supply frequency $=50 \mathrm{~Hz} ;$ \\
\hline Stator Data & Rotor Data \\
\hline Design parameters & Values & Design parameters & Values \\
\hline Outer Diameter & $210 \mathrm{~mm}$ & Outer Diameter & 147.3 \\
\hline Inner Diameter & $148 \mathrm{~mm}$ & Inner Diameter & 48 \\
\hline Number of slots & 48 & Number of slots & 44 \\
\hline Winding type & Single layer lap type & Winding type & Bar conductor \\
\hline
\end{tabular}

Table 1: Design Parameters of the Proposed Four Speed MPMPIM Drive

Finite element model of the MPMPIM in study is developed using Ansys Maxwell 2D. To validate the proposed design, 48 slot single layer lap winding is employed. FEA simulation results presented in this section validate all the four pole-phase combinations. Fig.2 (a) shows the flux line distribution for the 3phase 8-poleoperation which is better suited for hill climbing and starting where torque requirements are higher. 6-phase 4-pole combinations represented in Fig 2(b) shows high power configuration which is conducive for high speed and cruising requirements. 


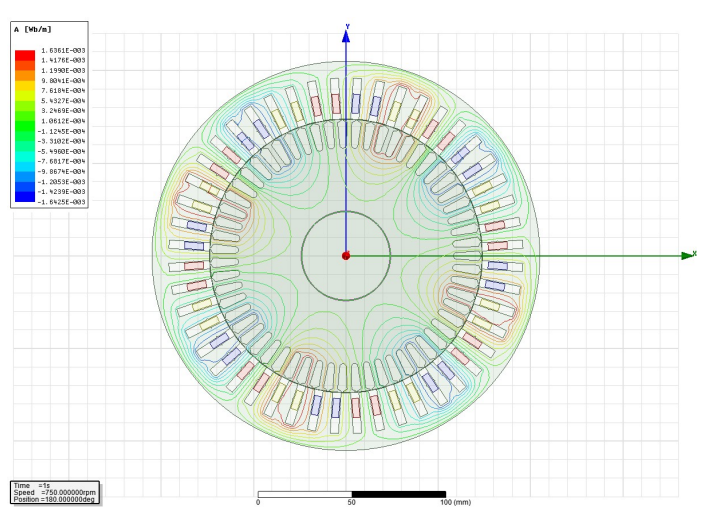

(a)

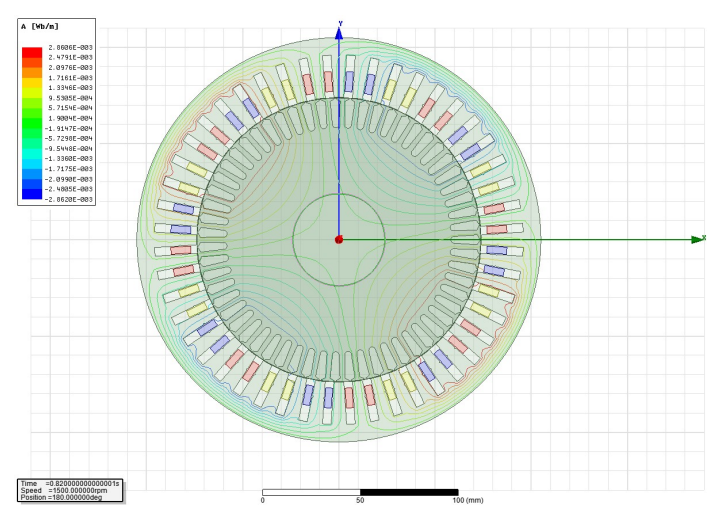

(b)

Fig. 2: Magnetic Field for Different Pole Phase Combination (a) 3-phase 8-pole (b) 6-phase 4-pole

\section{Design of Inverter for Proposed MPMPIM Drive}

Fig. 3 shows the stator winding supplied with a multi-phase inverter (12-phase). As indicated earlier, 48 stator slots were taken. Two adjacent slot conductors are connected in series in such a way that their incoming terminal is connected to centre tap of half bridge inverter and outgoing terminal is connected to star point. The current in each slot can be determined individually. The multi-phase supply can be achieved using modern power electronic switching devices such as MOSFETs or IGBTs.

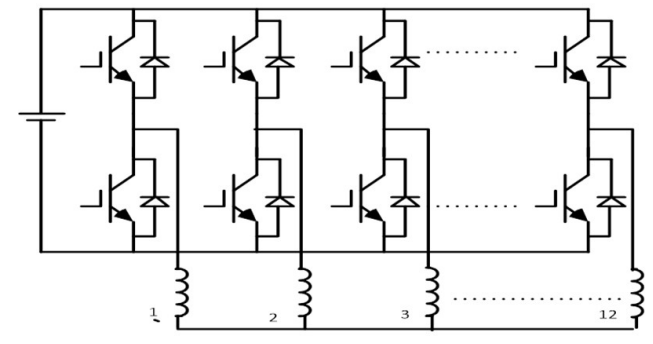

\section{Conclusions}

Fig. 3: m-phase Stator Winding Supplied with Multi-phase Inverter

From the initial analysis of the 48 slot MPMPIM, it can be inferred that the variable torque-speed characteristics can be achieved using the proposed method. The constraint of the pole ratio to be a positive odd integer greater than one can be extended to also include even integers. This has been proven by the simulation done in this work. However, mathematical analysis and physical hardware verification needs to be carried out. Also controlling the voltage and frequency of corresponding pole-pair separately enhances the fault tolerance capability with better performance under faulty conditions. Mathematical analysis and hardware implementation of the proposed drive with an effective control scheme is the future objective of the author.

\section{References}

1. C. C. Chan, 2007, The state of the art of electric and hybrid vehicles, IEEE, 95:704-718.

2. M.Ehsani., Y.Gao and J.M.Miller, 2007, Hybrid Electric Vehicle:Architecture and Motor Drives, 95:719-728

3. Z. Q. Zhu and C. C. Chan, 2008, Electrical machine topologies and technologies for Electric, Hybrid, and Fuel Cell Vehicles, IEEE Veh. Power Propul. Conf., 1-6.

4. G. Pellegrino, A. Vagati, B. Boazzo, and P. Guglielmi, 2012, Comparison of induction and PM synchronous motor drives for EV application including design examples, IEEE Trans. Ind. Appl., 48:2322-2332.

5. T. Wang, P. Zheng, Q. Zhang, and S .Cheng, 2005, Design characteristics of the induction motor used for hybrid vehicle, IEEE Trans. on magnetics,41:505-508.

6. R. Bojoi, S. Rubino, A. Tenconi, and S. Vaschetto, 2016, Multiphase electrical machines and drives: a viable solution for energy generation and transportation electrification, EPE,

7. Z. Q. Zhu, D. Howe, 2007, Electrical machines and drives for electric, hybrid, and fuel cell vehicles, Proc. IEEE, 95:746-765.

8. B. S. Umesh and K. Sivakumar, 2016, Dual-inverter-fed pole-phase modulated nine-phase induction motor drive with improved performance, IEEE Trans. Ind. Electron., 63:5376-5383. 
9. Kshirsagar, R. S. Kaarthik, K. Gopakumar, L. Umanand, and K. Rajashekara, 2017, Low switch count nine-level inverter topology for open end Induction Motor drives,IEEE Trans. Ind. Electron., 64:10091017.

10. B. S. Umesh and K. Sivakumar, 2016 Multilevel Inverter Scheme for Performance Improvement of Pole Phase Modulated Multiphase Induction Motor Drive, IEEE Trans. Ind. Electron., 63:2036-2043.

11. B.Prathap Reddy, K.Sivakumar, 2019 , Linear modulation range and torque ripple profile improvement of PPMIM drives, IEEE Trans. On Power Electronics, 34:12120-12127

12. J.Apsley and S.Williamson, 2006, Analysis of multiphase induction machines with winding faults, IEEE Trans. Industry Appl., 42:465-472

13. B. Prathap Reddy, M. Rao A, M. Sahoo, and S. Keerthipati, 2018, A Fault-Tolerant Multilevel Inverter for Improving the Performance of a Pole-Phase Modulated Nine-Phase Induction Motor Drive, IEEE Trans. Ind. Elect, vol. 65:1107-1116

14. Dongsen Sun, Baoming Ge, and Daqiang Bi, 2013, Winding design for pole-phase modulation of induction machines, IEEE Transactions on magnetics, 49

15. B. Ge, D. Sun, W. Wu, and F. Z. Peng, 2013, Winding design, modeling, and control for pole-phase modulation induction motors, IEEE Trans. Mag., 49:898-911.

16. B. S. Umesh, and Sivakumar K, 2014, Multiphase induction motor drive with 1:3:9:15 speed ratios for gear free electric vehicle application, $7^{\text {th }}$ International Conference on information and automation on sustainability, Sri Lanka.

17. B. S. Umesh, and K. S. Kumar, 2017, A five speed 45-phase induction motor drive with pole phase modulation for electric vehicles, IEEE International Conference on Industrial Technology (ICIT), Toronto, ON, 258-263.

18. Gautam, J.O. Ojo, 2012, Variable speed multiphase induction machine using pole phase modulation principle, IEEE Proc. Annu. Conf. Ind. Elect. Society, Canada, 3659-3665. 